Revista de la red interuniversitaria de estudios sobre las literaturas rioplatenses contemporáneas en Francia

$14 \mid 2016$

Levrero

\title{
Una escritura de rescate. El discurso vacío en la obra de Levrero
}

Reinaldo Laddaga

(2) OpenEdition

Journals

Edición electrónica

URL: http://journals.openedition.org/lirico/2199

DOI: 10.4000/lirico.2199

ISSN: 2262-8339

Editor

Réseau interuniversitaire d'étude des littératures contemporaines du Río de la Plata

\section{Referencia electrónica}

Reinaldo Laddaga, "Una escritura de rescate. El discurso vacío en la obra de Levrero », Cuadernos LIRICO [En línea], 14 | 2016, Puesto en línea el 07 junio 2016, consultado el 30 abril 2019. URL : http:// journals.openedition.org/lirico/2199; DOI : 10.4000/lirico.2199

Este documento fue generado automáticamente el 30 abril 2019.

\section{(c) $(1) \odot \ominus$}

Cuadernos LIRICO está distribuido bajo una Licencia Creative Commons Atribución-NoComercialSinDerivar 4.0 Internacional. 


\title{
Una escritura de rescate. El discurso vacío en la obra de Levrero
}

\author{
Reinaldo Laddaga
}

1 ¿A qué se debe el interés que ha despertado en los últimos años la obra de Mario Levrero? Durante décadas fue un escritor de estricto culto. Sería exagerado decir que ahora es popular, pero sus libros salen en editoriales de considerable distribución, se publican colecciones de ensayos críticos, revistas y suplementos literarios le dedican notas y dossiers. Tal vez me equivoque, pero pienso que lo que ha inducido el rescate de esta obra que pudo haberse perdido en la pila siempre creciente de libros que no encuentran sus lectores es, sobre todo, la narrativa que el escritor produjo en la última década y media de su vida : El discurso vacío, El alma de Gardel, La novela luminosa. El entusiasmo de los lectores por esta obra es curioso : no es inmediatamente evidente que esté hecha para suscitar el entusiasmo. ¿Pero qué otra cosa quisiera suscitar? El volumen que inicia esta serie tardía de textos atípicos, El discurso vacío, lo dice con perfecta claridad. Por eso, más bien que ofrecer una interpretación, este ensayo quiere proponer una breve colección de citas de Levrero provenientes de ese libro y de entrevistas dadas por la época de su escritura, colección ordenada de manera de ayudar a los lectores, si es que necesitan esta ayuda, a observar la serie en cuestión a través del lente por el que él hubiera querido que la observáramos.

2 El propio Levrero pensaba que El discurso vacío era un libro especial entre sus libros. En primer lugar, se había escrito solo; en segundo lugar, había sido rescatado en el último momento de las llamas que iban a destruirlo. Las dos cosas le otorgaban, desde la perspectiva del escritor, un valor particular. Así describe él mismo, en una entrevista en que le preguntan por su último libro, por entonces aún inédito, el momento en que lo concluye :

Es una novela que se escribió sola. Se llama "El discurso vacío" y tiene dos partes mezcladas. Una es "El discurso vacío" propiamente dicho y la otra, más extensa, se llama "Ejercicios". Son ejercicios de caligrafía que hacía para mejorar la letra, o dicho de otro modo, mejorar mi personalidad a través de la letra. Así como los grafólogos aseguran que en la letra se puede ver la personalidad, hay quienes 
sostienen que si cambiás la letra podés mejorar algunas cosas de tu vida interior. No creía en eso pero necesitaba tener buena letra y escribía una hoja por día. Se las dejaba a mi mujer para que les echara un vistazo. Con el tiempo esas páginas se convirtieron en mensajes a ella, que no estaba en todo el día por cuestiones de trabajo. Ahí escribía cosas que tenía que comunicarle, muchas protestas con ella, indicaciones. Entonces fueron acumulándose un montón de hojas durante un año y medio. Al mismo tiempo nació un texto en el que escribía de cosas personales, pero ya con intención literaria, y terminó siendo la historia de un perro y un gato. Un día hice una limpieza del escritorio y me propuse quemar la montaña de ejercicios de caligrafía en la parrilla del fondo, donde hacíamos asados. Mientras las llevaba, el inconsciente me hizo leer una frasecita y dije: Ah, no, esto me interesa, lo voy a leer. Era una novela, y estaba terminada. La pasé en limpio y le inserté el otro texto. Los amigos que la leyeron, incluida mi esposa, aseguran que es lo mejor que he escrito. ${ }^{1}$

El escritor, camino a la parrilla, lee casi por accidente una frase que ha escrito y descubre que las hojas que lleva en las manos alojan algo que no había reconocido y que tiene importancia ; en el último instante, el escritor salva sus hojas del fuego al entender que en ellas se han depositado huellas de alguien que no es él pero que solo puede manifestarse por medio de él. Esta es una de las figuras centrales en el drama compuesto durante décadas por el escritor : Mario Levrero, el autor de la literatura que identifica ese nombre, no es Jorge Varlotta, la persona que realiza los trámites que le permiten mantenerse en vida para que, en ocasiones, Mario Levrero deje en el mundo huellas de su elusiva existencia. "Cuando escribí La ciudad y había que ponerle una firma -dice otra entrevistayo sentía que no podía firmarla con mi nombre habitual porque esa obra no era completamente mía. Despues fui descubriendo que estoy habitado por un escritor y que Jorge Varlotta no puede escribir nada literario"2. Hay dos personas en este cuerpo, pero la segunda es más bien insustancial. Mario Levrero, según Jorge Varlotta lo imagina, es un proceso que se desencadena cuando ciertos elementos del individuo y su mundo entran en contacto : "El escritor es un ser misterioso que vive en mí, y que no se superpone con mi $y o$, pero que tampoco le es completamente ajeno. Afinando un poco más la percepción, podría decir que el escritor se crea en el momento de escribir, por la confluencia del yo con otros estratos, núcleos o intereses del ser"3.

4 El atractivo de los libros tardíos de Levrero depende, en parte, de que no nos parece que estén escritos para que nos gusten : son carpetas que contienen informes de alguien que, aunque evidentemente melancólico, se ha librado de la necesidad, común entre literatos, de escribir textos admirables. En cada uno de estos libros, alguien, siempre el mismo en su continua vaguedad, se pone a resolver un problema y nos permite observar los instrumentos de su tarea y los restos en forma de texto de la operación. La literatura sucede cuando el escritor se ocupa de otras cosas : "Yo siempre pensé que la literatura es como un producto secundario de un proceso espiritual que inicialmente no está dirigido a la literatura. En el momento de ponerse a escribir se trata de resolver algún problema que no tiene solución desde ningún otro ángulo que lo enfoque. Como, por ejemplo, algunas imágenes torturantes de un sueño que no te abandonan y te persiguen, días y días. Decís, bueno, ahí hay algo y empezás a escarbar como medio de reconstruir el mundo que dio origen a esa imagen inicial perturbadora"4. Solo que "escarbar" es, simplemente, continuar escribiendo, porque "hay cosas que no las integro si no pasan por los dedos y no son recogidas por la vista" 5 .

5 Los que hayan leído El discurso vacío saben que esto es lo que se propone hacer el personaje que se constituye en la sucesión de páginas donde se presenta no como alguien que se propone escribir un libro sino como alguien que realiza modestos ejercicios. Casi 
desde el principio, luego del prólogo que forman dos poemas (o un poema en dos partes) y el relato de un sueño, el libro comienza a desplegar una serie abierta de ejercicios de "autoterapia grafológica" destinados a mejorar la letra manuscrita para mejorarse la salud y el carácter. El éxito de la terapia depende, piensa el sujeto de estos ejercicios, de su capacidad de resistir a la voluntad de decir algo, de prestar atención a los contenidos de las frases en lugar de la forma de las letras. Estos fragmentos debieran ser perfectamente "planos" : cosas escritas por alguien que se esfuerza por poner un dique a la tentación de "transformar mi prosa caligráfica en prosa narrativa"6, a la vez que sospecha que está "inaugurando tal vez una nueva época del aburrimiento como corriente literaria"7.

6 Y, sin embargo, un poco a espaldas del individuo que se ocupa en su terapia, algunos temas comienzan a delinearse, y la prosa caligráfica oscila hacia la prosa narrativa. Los temas gravitan en torno a su lamento al constatar que lleva una existencia dispersa, trivial, abúlica, presa de las interrupciones de la vida práctica : "Hace un rato-escribe- le decía a Alicia que me sentía mal porque hace mucho tiempo que no me conecto con la eternidad. Esto quiere decir que percibo las cosas superficialmente, que no tengo vivencias, que estoy apartado del Ser Interior; demasiado apartado, y sin tener la menor noción de los caminos posibles para acercarme"8. Jorge Varlotta, en el comienzo de $\mathrm{El}$ discurso vacío, ocupa del todo una escena que Mario Levrero ha abandonado o que ha dejado de visitar. ¿O no ? Todavía no lo sabemos, pero ya se ha producido (seguramente desde el principio de la autoterapia grafológica) la combinación que desencadena el proceso de generación en el texto del escritor : la aparición de Mario Levrero se prepara. Una literatura que es como un producto secundario de un proceso que es espiritual a fuerza de ser físico (la transformación de la mente por la transformación de la escritura) ha empezado a producirse, pero Varlotta todavía no lo sabe (aunque probablemente lo sepa mucho antes que se produzca la escena de reconocimiento que mencionaba su entrevista). La magia que en ciertas condiciones está asociada a la escritura ha comenzado a operar. Es que "este tipo de escritura tiene unos efectos mágicos incontrolables"9 (siempre, por otra parte, potencialmente peligrosos). Se trata de la magia comun de la escritura "realista" : "Cuando trato de tocar lo que llaman realidad -sigue-, cuando mi escritura se vuelve actual y biográfica, resulta inevitable poner inconscientemente en juego esos misteriosos y muy ocultos mecanismos, los que al parecer comienzan a actuar secretamente y a producir algunos efectos perceptibles"10.

7 Podemos considerar ingenua la creencia del escritor en que puede transformarse a sí mismo por la vía de establecer una práctica de escritura manuscrita. Pero eso sería desestimar que ciertos esquemas orientan y ordenan la visión del mundo que comunican estos libros. Un esquema particularmente importante es el que indica que "uno es uno mismo pero también es su entorno ; el sí mismo se prolonga y se proyecta en el entorno, y un desajuste de este último desajusta todo el psiquismo" ${ }^{11}$. Esta creencia está en la base de las estrategias cuya descripción es el objeto principal de los últimos libros de Levrero, llegando a una suerte de apoteosis en La novela luminosa. Por eso es que el acceso a la dimensión más profunda de sí mismo se produce por la manipulación de las circunstancias, el espacio en el que el cuerpo se mueve y el tiempo que lo atraviesa. Por eso el drama principal en estos libros es el del acomodamiento de la casa y la perturbación más grave tener que abandonarla, incluso si se trata solamente de dar un paseo o cumplir un trámite (y tanto más si el evento es una mudanza). Por eso hacia el final de El discurso vacío el escritor se encuentra intentando, despues de sucesivos 
abandonos y reencuentros, "recomenzar aquel viejo trabajo sobre mi letra para tratar de irme rescatando cada vez más ampliamente. Imagino que el cultivo de este hábito, más que el de otros hábitos positivos que iré incorporando en los días sucesivos, me dará un ritmo, una pauta, una base sobre la cual edificar mi manera de vivir en esta nueva casa y en este nuevo tiempo que con ella iniciamos"12.

"Irme rescatando cada vez más ampliamente": ¿qué significa esto? En un pasaje particularmente revelador Levrero escribe : "Cree la gente, de modo casi unánime, que lo que a mí me interesa es escribir. Lo que me interesa es recordar, en el antiguo sentido de la palabra (= despertar) ${ }^{113}$. Este párrafo aclara lo que la entrevista que comencé por citar sugería :

Si escribo es para recordar, para despertar el alma dormida, avivar el seso y descubrir sus caminos secretos; mis narraciones son en su mayoría trozos de la memoria del alma, y no invenciones.

El alma tiene su propia percepción y en ella viven cosas de nuestra vigilia pero también cosas particulares y exclusivas de ella, pues participa de un conocimiento universal de orden superior, al cual nuestra conciencia no tiene acceso de forma directa. De modo que la visión del alma, de las cosas que suceden dentro y fuera de nosotros, es mucho más completa que lo que puede percibir el yo, tan estrecho y limitado. ${ }^{14}$

"Irme rescatando cada vez más ampliamente" equivale, entonces, a "despertar el alma dormida". Levrero profesaba un heterodoxo y torturado platonismo: conocer es despertar en sí mismo ciertas latencias, potencialidades de manifestación que pueden, en condiciones adecuadas, desplegarse. Conocer, en el sentido más profundo, es recordar lo que ya posee, un poco desde siempre, el alma, entidad de naturaleza enigmática. La práctica de la escritura puede inducir este conocimiento siempre que el escribiente no se obstine en comunicar significaciones específicas sino que practique la sistemática, disciplinada enunciación de un discurso vacío.

"El discurso vacío" es no solamente el título del libro sino también el de la segunda cadena de textos cuya composición tenía lugar al mismo tiempo que los ejercicios grafológicos. Esta cadena comienza, si vamos a creerle al sistema de fechas que nos propone el texto, dos meses más tarde que la otra, justamente cuando la escritura terapéutica le hace descubrir al escritor la reanimación de su antiguo deseo de realizar un "acto narrativo libre"15. Vale la pena citar el comienzo de esta cadena de fragmentos :

Hay un fluir, un ritmo, una forma aparentemente vacía ; el discurso podría tratar cualquier tema, cualquier imagen, cualquier pensamiento. Esa indiferencia es sospechosa; presiento que tras la apariencia de vacío hay muchas, demasiadas cosas. El vacío nunca me asustó demasiado; en ocasiones hasta llegó a ser un refugio. Lo que me asusta es no poder huir de ese ritmo, de esa forma que fluye sin develar sus contenidos. Por eso me pongo a escribir, desde la forma, desde el propio fluir, introduciendo el problema del vacío como asunto de esa forma, con la esperanza de ir descubriendo el asunto real, enmascarado de vacío.

No quiero forzar las cosas con imágenes del pasado o explicaciones de la situación presente, que siempre suenan falsas : me gustaría dejar hablar a esa forma para que se fuera delatando por sí misma, pero ella no tiene que saber que yo espero que se delate porque enseguida se me escurriría otra vez hacia la apariencia de vacío. Tengo que estar alerta, pero con los ojos entornados, con un aire distraído, como si no importara el discurso que se va desarrollando. Es como entrar en un estanque con peces, y esperar que se aquieten las aguas agitadas y los peces se olviden de que algo agitó las aguas, y se acerquen, y comiencen a pasear su curiosidad próximos a mí y a la superficie del estanque ; entonces podré verlos y, tal vez, atrapar a alguno. 16 
11 El texto es suficientemente claro: no hace falta comentarlo. Pero si es útil subrayar la analogía que propone entre la escritura, cuando se hace como se debe, y la pesca. Escribir es como preparar una red o un gancho destinados a capturar algo que por naturaleza es evasivo. ¿Evasivo para quién? Para el que se sienta a la mesa de escritura como un pescador se sienta a la orilla de una corriente de agua. Para el yo, segun el nombre que normalmente le da Levrero a la parte de sí mismo que trata con los asuntos prácticos y que es, piensa, "una parte modificada, en función de cierta conciencia práctica, de un vasto mar que me trasciende y sin duda no me pertenece; un espécimen surgido, o emergente, de un vasto mar de ácidos nucleicos"17. El yo es una cristalización que se produce entre un mundo de cosas que tienen el poder de afectar íntimamente al individuo y un alma que "tiene su propia percepción", que "participa de un conocimiento universal de orden superior". Los fragmentos flotantes provenientes de esta dimensión, fragmentos que sin embargo no se habrían producido si el yo no se hubiera empeñado en la tarea metódica de una escritura que no comunicara nada en particular, son los que los libros debieran retener.

El discurso vacío, entonces, es una muestra de las "ruinas del alma", la exposición parsimoniosa de los fragmentos flotantes que llegan al sitio donde tiene lugar la escritura. Por cierto, esta palabra, "ruinas", es la clave de un pasaje que es especialmente importante porque establece el vínculo entre el propósito práctico del libro y la clase especial de belleza que Levrero prefería (belleza que, por cierto, es la que asegura el atractivo de las novelas tardías, si es que eso es lo que son). Tal vez en ningún otro momento de su obra el escritor detalle con más nitidez su poética. El contexto es la declaración de su desacuerdo con Dylan Thomas en ocasión de la lectura de una de sus cartas donde "decía que no podía considerar hermosa ninguna cosa efímera; que la belleza es cuestión de eternidad"18. Nada de eso, piensa Levrero, y su convicción es enseguida reforzada por la audición de "un tema popularizado hace años por la orquesta de Enrique Rodríguez".

Me produjo -sigue- una sensación deliciosa, y de inmediato se me presentó la imagen de un gran galpón o una barraca que habíamos visto con mi mujer días atrás en una playita cercana al hipódromo ; un viejo edificio lleno de vidrios. En aquel momento había deseado tener una cámara fotográfica para retratar ese paisaje de vidrios (algunos sanos, muchos rotos) en la luz especial de la puesta de sol. Y además de esos vidrios había maquinarias y bobinas abandonadas entre pastizales y yuyos. Delicioso : me produce un placer casi erótico la contemplación de ciertas ruinas, de casas abandonadas, de casas demolidas, sobre todo cuando son invadidas por la vegetación.

Recuerdo ahora una casa en Pan de Azúcar, abandonada o bien sin terminar, casi un esqueleto de casa; tal vez haya sido abandonada antes de terminarse de construir. A través del hueco de una ventana salía la rama de un árbol crecido en su interior. Diga lo que diga Dylan Thomas, esto es belleza para mí. Como es belleza, y constituyó según creo mi primera vivencia místico-religiosa auténtica, la contemplación -en ese mismo camino que desde Piriápolis lleva a Pan de Azúcarde una iglesia abandonada, cayéndose materialmente a pedazos, y con un horrible cristo de madera sobre el portal (después me contaron que ese cristo había llegado a la costa flotando en las olas del mar). ${ }^{19}$

13 Lo que es auténticamente significativo es que, al final de este pasaje, tras la queja por la falta de aprecio de su mujer por Enrique Rodríguez, el escritor dice que también él puede (como ella) gozar de Bach y de Vivaldi, pero la canción de Enrique Rodríguez pertenece a la misma dimensión que sus adoradas ruinas invadidas por la vegetación, que "eso es lo que me dice su música y lo que hoy, después del desayuno, se sumó a mi discusión secreta 
con Dylan Thomas y al recuerdo de la puesta de sol en la playita próxima al hipódromo. Y así fue como rescaté una pieza esencial de mí mismo, perdida en medio del fragor de estos últimos años"20.

Este es el único rescate que el libro reconoce con todas las letras, su único momento de triunfo explícito. "Hoy recuperé - prosigue- esos distintos tipos de ruinas, y sé que con eso el alma me está diciendo que yo soy esas ruinas. Mi contemplación casi erótica de las ruinas es una contemplación narcisista. Y si bien tiene su precio, esa autocontemplación es placentera aunque la visión sea triste"21. Es necesario notar que lo que aquí ejemplifica o encarna la belleza no es una casa terminada sino, al contrario, edificios en construcción o en, bueno, destrucción, pilas irregulares de ladrillos, vidrios quebrados por el suelo, estatuas levantadas por el mar.

Una escena semejante, donde una visión repentina desencadena una experiencia de aquello de sí mismo que usualmente está en fuga pero que, al presentarse, ofrece una clave sobre la manera deseable de vivir, aparece en el epílogo, tres páginas sueltas que incluyen dos fragmentos que son variaciones de las páginas sueltas del principio. La escena está consignada en un fragmento de la serie de "el discurso vacío" donde el escritor se lamenta una vez más de la situación de dependencia en la que está, incapaz de practicar cabalmente lo que va tratando de practicar. Es, una vez más, el crepúsculo.

Sin embargo hoy vi, hacia la caída del sol, el reflejo de unos rayos rojizos del sol en unos ladrillos de cerámica barnizada, y me di cuenta de que aún estoy vivo, en el verdadero sentido de la palabra, y de que aún puedo llegar a situarme en mí mismo : todo es cuestión de encontrar cierto punto justo, mediante cierta voltereta espiritual ; no puedo evitar la maraña de consecuencias, no puedo pretender ser el protagonista, otra vez, de mis acciones, pero sí me es posible rescatarme dentro de esas nuevas pautas, aprender a vivir otra vez, de otra manera. Hay una forma de dejarse llevar para poder encontrarse en el momento justo en el lugar justo, y este 'dejarse llevar' es la manera de ser el protagonista de las propias acciones -cuando uno ha llegado a cierta edad"22.

"Dejarse llevar", entonces : esta es la "voltereta espiritual" que, en tiempos de dispersión, es necesario realizar para recoger los "trozos de la memoria del alma" y disponerlos de modo que puedan ser objeto de la contemplación narcisista y casi erótica que es, para el autor, el objetivo principal de su existencia. En el otro extremo del libro, el prólogo enumeraba varias de estas ocasiones de contemplación. "He visto a Dios", comienza la segunda parte del poema sin título que abre el libro, "cruzar por la mirada de una puta / hacerme señas con las antenas de una hormiga / hacerse vino en un racimo de uvas olvidado en la parra / visitarme en un sueño con el aspecto repulsivo de una babosa gigantesca / he visto a Dios en un rayo de sol que oblicuamente animaba la tarde ; / en el buzo violeta de mi amante después de una tormenta ; / en la luz roja de un semáforo / en una abeja que libaba empecinadamente de una florcita / miserable, mustia y pisoteada, en la plaza Congreso; / he visto a Dios incluso en una iglesia"23. Las apariciones que la contemplación identifica forman una serie de procesos marcados por una temporalidad de alguna manera convulsiva. Son pequeños remolinos: rayos de sol o resplandores del semáforo ; un buzo violeta que se manifiesta despues de la tormenta ; las antenas de una hormiga que se agitan ; un rayo que anima el cielo de la tarde ; una abeja que absorbe los últimos nutrientes de una flor que la próxima pisada pulverizará. En cada uno de estos casos el escritor se encuentra en el "lugar justo", en el instante que precede a la definitiva destrucción de las criaturas que contempla, como debe haberse encontrado en el "lugar 
justo" en el momento declinante en que caminaba en dirección a la parrilla donde iba a quemar los restos de sus ejercicios.

La primera parte del poema que acabo de citar abre el arco de este libro que se cierra con otra prenda violeta, idéntica y diferente al buzo que, despues de la tormenta, se sostiene del cuerpo de la amante ("Hace pocos días -dicen las últimas líneas del epílogo- soñé con un grupo de curas que estaban vestidos cada uno con una sotana de color diferente; recuerdo en particular a uno de ellos, cuya sotana era de color violeta muy vívido. Ellos adoptaban ciertas posiciones y ciertas combinaciones en las posiciones del grupo, y yo entendía que de esa forma estaban expresando el secreto de la Alquimia"24). Abre este arco que el epílogo cierra con una postulación : "Aquello que hay en mí, que no soy yo, y que busco. / Aquello que hay en mí, y que a veces pienso que / también soy yo, y no encuentro. / Aquello que aparece porque sí, brilla un instante y luego / se va por años / y años"25. Pronto sabremos que esta entidad inapresable es la que la escritura quisiera manifestar, aunque las maniobras que realice deban ser muy discretas, como las del que entra a un estanque tratando de no agitar el agua, así no se espantan los peces : porque a aquello que apenas nombra "es inútil buscarlo; cuanto más se lo busca / más remoto parece, más se esconde"26. Hay que moverse a ciegas, como lo hace cierto conejo en un sueño que se relata en este mismo prólogo, que "se encuentra sepultado por la nieve y cava galerías en la nieve, moviéndose rápidamente de un lado a otro. Me entra la preocupación de que pueda golpearse contra algo, un árbol o una piedra, porque va a tientas; pero luego me entero de que ha aprendido a comunicarse, mediante un sistema que en el sueño se explicaba detalladamente, con una paloma que volaba por encima de su cabeza, y por encima de la nieve, y lo iba guiando en su recorrido"27. Así le gustaría verse al escritor en trance "de dejarse llevar para poder encontrarse en el momento justo en el lugar justo"28. El programa que de esa manera establece El discurso vacío, programa deliberadamente crepuscular que consiste en la construcción de edificaciones incompletas que dejen aparecer formaciones irregulares y escuálidas, es el que Mario Levrero cumplirá en lo que le quedan de años y días. La primera ejecución del programa toma esta forma : retener una serie de fábulas o sueños que crecen como a partir de sí mismos, "actos narrativos libres" que se dejen entrever a través del marco en sí mismo pobre que forman las páginas de registro de una cierta autoterapia grafológica (abandonadas primero en partes de la casa para que su mujer las encontrara, abandonadas luego en algún cajón, abandonadas casi al fuego pero recobradas en el último instante), como sale del hueco de una ventana de una casa inconclusa para siempre la rama de un árbol que ha crecido, sin que nadie lo plantara, en su interior. La belleza de la arquitectura de este libro, seguramente pensaba el escritor, se parece menos a la de Bach o Vivaldi que a la de Enrique Rodríguez, pero esto no hace que sea menos digna de sus operaciones de rescate. 


\section{NOTAS}

1. Mario Levrero, Un silencio menos. Conversaciones compiladas por Elvio E. Gandolfo, Buenos Aires : Mansalva, 2013, p. 133.

2. Ibid., p. 108.

3. Ibid., p. 118.

4. Ibid., p. 111.

5. Ibid., p. 111.

6. Mario Levrero, El discurso vacío, Buenos Aires : Mondadori, 2014, p. 43.

7. Ibid., p. 40.

8. Ibid., p. 46.

9. Ibid., p. 119.

10. Ibid., p. 119.

11. Ibid., p. 156

12. Ibid., p. 156.

13. Ibid., p. 146.

14. Ibid., p. 146.

15. Ibid., p. 52.

16. Ibid., pp. 53-54.

17. Ibid., p. 147.

18. Ibid., p. 143.

19. Ibid., pp. 143-144.

20. Ibid., p. 145.

21. Ibid., p. 147.

22. Ibid., pp. 202-203.

23. Ibid., p. 12.

24. Ibid., p. 203.

25. Ibid., p. 11.

26. Ibid., p. 12.

27. Ibid., p. 14.

28. Ibid., pp. 202-203.

\section{RESÚMENES}

Los libros tardíos de Mario Levrero son entregas sucesivas de su cuaderno de ejercicios (espirituales, mentales, corporales). En estos trabajos la escritura se presenta como el medio adecuado para recobrar, en los fragmentos que compone alguien que no sabe del todo lo que hace, la presencia momentánea de un sujeto que solo puede capturarse en fuga. Mi ensayo analiza la manera como este proceso se presenta en su libro El discurso vacío, y propone una 
manera de abordar estos enigmáticos volúmenes a partir de las lecciones de lectura que contienen.

Les derniers livres de Mario Levrero sont des fragments, tirés d'une sorte de cahiers d'exercices (spirituels, mentaux, corporels). L'écriture se présente ici comme un moyen pour retrouver la présence momentanée d'un sujet qui ne peut être capturé que dans la fuite. Cet essai analyse ce processus dans Le discours vide et propose une interprétation de ces livres énigmatiques.

Mario Levrero's late novels are composed of fragments taken from his (spiritual, mental, bodily) exercise notebooks. In these works, writing is presented as a means to recover from those fragments, the passing presence of a subject that can only be captured in flight. My essay analyzes the way this process is described in his book El discurso vacio (The Empty Speech) and proposes an interpretative approach to his late enigmatic

ÍNDICE

Mots-clés: Mario Levrero, El discurso vacío, écriture, mémoire, technique du moi

Keywords: writing, memory, technologies of the self

Palabras claves: escritura, memoria, técnicas del yo

\section{AUTOR}

REINALDO LADDAGA

Escritor, crítico 